\title{
Children with Hearing Loss Health-Related Quality of Life and Parental Perceptions
}

\author{
Olga María Alegre de la Rosa ${ }^{1} \&$ Luis Miguel Villar Angulo ${ }^{2}$ \\ ${ }^{1}$ Department of Didactics and Educational Research, University of La Laguna, Santa Cruz de Tenerife, Canary \\ Islands, Spain \\ ${ }^{2}$ Department of Didactics and Educational Organization, University of Seville, Sevilla, Spain \\ Correspondence: Olga María Alegre de la Rosa. University of La Laguna, 38200 San Cristóbal de La Laguna, \\ Santa Cruz de Tenerife, Canary Islands, Spain.
}

Received: October 7, 2019

Accepted: November 17, 2019

Online Published: January 29, 2020

doi:10.5539/ies.v13n2p33

URL: https://doi.org/10.5539/ies.v13n2p33

\begin{abstract}
This study aimed to evaluate two objectives: first, the health-related quality of life (HRQoL) and socio-demographic characteristics of children with cochlear implants (CIs) or hearing aids (HAs) on the Kid-KINDL ${ }^{\mathrm{R}}$ _children_7-13 questionnaire, and second to analyze parental background factors and the perceptions of their children with CIs or HAs on the Kid_Kiddo-KINDL ${ }^{\mathrm{R}}$ Parents_ 7-17 questionnaire. The data consisted of 89 children with CIs and 63 children with HAs and their 89 parents, respectively. The characteristics of children and the parental factors included demographic and audiological variables. Student's $t$-test and one-way ANOVA were used to analyze the two objectives. Children with CIs exhibited a perception of better HRQoL in comparison with children with HAs. Among other differences, children with CIs or HAs and their parents were significantly distinct in the variable Setting $(t=2.921, p<0.010)$. Moreover, parents of children with CIs or HAs were significantly different among them in some background factors (i.e., age, socioeconomic status, and learning). Children with CIs and their parents demonstrated a perception of better HRQoL than children with HAs and their parents. These findings added to the existing knowledge about the benefits of CIs for children with hearing loss. Parents of children with CIs noted the significance of social and emotional development as a marker of well-being in their children's lives.
\end{abstract}

Keywords: children, cochlear implants, hearing aids, health-related quality of life (HRQoL), parents

\section{Introduction}

\subsection{The Problem}

The notion of health-related quality of life (HRQoL) affects an individual's health triangle, which includes bodily functions, social conditions, and mental fitness. Since the presentation of the quality of life (QoL) notion to researchers, over 20,000 documents documented this particular topic (Ravens-Sieberer \& Bullinger, 1998, p. 399). In this study we ask the following general question: what are the differences of HRQoL among children with hearing loss and their families in the Canary Islands?

\subsection{Importance of the Problem}

The notion of HRQoL has been surveyed, among other instruments, by the KINDL questionnaire. The original KINDL was developed in Germany and revised by two researchers (Ravens-Sieberer \& Bullinger, 2000). The psychometric properties of the $\mathrm{KINDL}^{\mathrm{R}}$ questionnaire satisfied the standards of reliability, validity, and sensitivity on scales for different contexts (languages, countries, diseases, and populations). Some researchers applied it to 2 population segments of Asian students comparing healthy students with children affected with diabetes (Wee, Lee, Ravens-Sieberer, Erhart, \& Li, 2005). At that time, researchers confirmed the total reliability and validity of each of the 6 subscales of the Chinese version of KINDL with healthy students (Lee, Chang, \& Ravens-Sieberer, 2008). Moreover, a group of researchers proved that the Nepali version of KINDL comprised relevant psychometric characteristics with healthy secondary school students: internal consistency, discriminant validity, reproducibility, interpretation, and response (Yamaguchi et al., 2010). Meanwhile, other scholars confirmed the structural base of KINDL and its 6 multidimensional subscales (Warner-Czyz, Loy, Tobey, Nakonezny, \& Roland, 2011). Furthermore, a research team verified the validity and reliability of the KIDSCREEN and KINDL questionnaires 
(Stevanovic, Tadic, Novakovic, Kisic-Tepavcevic, \& Ravens-Sieberer, 2013). However, lack of young children's comprehension of question-wording affected children's outcomes (Jardine, Glinianaia, McConachie, Embleton, \& Rankin, 2014). The KINDL's impact in practice was evident in other countries (e.g., Turkey and Iran) where researchers addressed different discourses (e.g., educational development, learning disabilities, and illness) (Sakiz, Sart, Börkan, Korkmaz, \& Babür, 2015; Rojhani Shirazi, Tonekaboni, Azargashb, Derakhshannia, \& Aghdasta, 2016).

Some investigators assessed HRQoL in children with cochlear implants (CIs), employing the internationally validated KIDSCREEN-27 survey and concluded that the instrument was comparable between implanted and non-implanted children (Razafimahefa-Raoelina et al., 2016). On the other hand, other researchers found that the original internal structure of 6 factors of Kiddo-KINDL was not satisfactory, because it presented dimensional instability (Navarro \& Merino, 2016). Nevertheless, the KiddyKINDL 3-7 years (Ravens-Sieberer \& Bullinger, 2000) was "an established, norm-referenced German measure of HRQoL for self- and parent report" (Neumann, Salm, Rietz, \& Stenneken, 2017, p. 677). Undoubtedly, the HRQoL of children aroused the interest of researchers due to its emphasis on the components of children's healthy well-being and, particularly, the influence treatment had on the quality of life (QoL) (Berger \& Karabenick, 2016; Karimi \& Brazier, 2016). This historical perspective helped to explain how this ambitious and research effort notion remained consistent (Hoffman, Cejas, \& Quittner, 2018).

\subsection{Social-Emotional and Behavioural Functioning}

The theoretical model of HRQoL assumed that involving students, teachers, and family cultures shaped children's social and cognitive development. Indeed, researchers suggested that school social climate and interpersonal relationships among pupils and their teachers were critical determinants of students' self-concept and engagement (Punch \& Hyde, 2011). In correlational studies, longer duration of implant use and higher children's self-esteem are evident. Both factors were associated with better team performance in the peer task, which in turn was related to the parents' reports on the social performance of children outside an exploratory setting (Martin, Bat-Chava, Lalwani, \& Waltzman, 2011). The findings of cochlear implantation in deaf children agreed on the improvement in speech perception, speech intelligibility, and communication and language development (Edwards, Hill, \& Mahon, 2012). However, children with CIs were less skilful than children with normal hearing in all tasks concerning emotions (Wiefferink, Rieffe, Ketelaar, De Raeve, \& Frijns, 2013). Generally, research findings vary between children with CIs and healthy hearing. While some results revealed similarities between the emotional abilities of healthy and deaf children (Ziv, Most, \& Cohen, 2013), other findings evidenced that children with hearing loss, in comparison to their peers with normal hearing, were at high risk of fatigue (Hornsby, Werfel, Camarata, \& Bess, 2014). Further, children with CIs reported concerns about social and school functioning, according to Haukedal, Lyxell, and Wie (2019), when they were assessed by the generic questionnaire Pediatric Quality of Life Inventory. Finally, studies found benefits in the social competence of children with CIs or HAs (Muñoz et al., 2016; Freeman, Pisoni, Kronenberger, \& Castellanos, 2017).

\subsection{Family QoL of Families Raising Children with CIs or Has}

Most researchers had not sufficiently established the agreement between CIs or HAs children's self-reports and parent's reports for HRQoL measures (Stevanovic et al., 2013). Moreover, analysts provided a systematic evaluation of those variables that affected the children-parents agreement coefficients (Sakiz et al., 2015).

The notion of parents' tensions was examined in different ways. Thus, although parents of children with bilateral CIs were significantly less stressed than parents of children with unilateral CIs in a study (Sarant \& Garrard, 2014), parents of deaf children perceived slightly fewer feelings of a provocation than children and adolescents in another study (Duarte, Santos, Rego, \& Nunes, 2014). More specifically, parents positively rated most HRQoL domains, although education and the effects of implantation received significantly fewer positive ratings (Kumar, Warner-Czyz, Silver, Loy, \& Tobey, 2015). Other parents within the parenting styles paradigm advocated rational information sessions with language specialists for developing parent-significant theoretical knowledge (Veland, Bru, \& Idsøe, 2014; Narr \& Kemmery, 2015). Later studies demonstrated wide-ranging findings. In a piece of research using the Pediatric Quality of Life Inventory, parents of children with CIs reported statistically significant poorer HRQoL in their children (Haukedal, von Koss, Lyxell, \& Wie, 2018), whereas other parents using Children with Cochlear Implants: Parental Perspectives were satisfied with HRQoL, especially with the domain of social relations (Zhao et al., 2018). Additionally, in all social-emotional functioning variables of the Strengths and Difficulties Questionnaire (SDQ; Goodman, 1997) there appeared a tendency in which "parents of children with CIs reported better functioning of their children than parents of children with HAs" (Michael, Attias, \& Raveh, 2019, p. 29). 


\subsection{Research Questions}

The study addressed the following two research questions:

How do the 6 dimensions of HRQoL—including Physical well-being, Emotional well-being, Self-Esteem, Family, Friends, and Everyday Functioning (School or Nursery School) - and socio-demographic characteristics of primary school children using CIs contrast information to primary school children using HAs by the version of Kid-KINDL ${ }^{R}$ children_7-13?

How background factors of primary school children's parents with CIs perceive the 6 dimensions of HRQoL of their children - including Physical well-being, Emotional well-being, Self-Esteem, Family, Friends, and Everyday Functioning (School or Nursery School) — compared with background factors of primary school children's parents with HAs by the version of Kid_Kiddo-KINDL ${ }^{R}$ Parents_ $_{-}$7-17?

\section{Materials and Methods}

\subsection{Participants}

Respondents included all children with CIs or HAs and their parents. The Association of Parents of Children with Cochlear Implants of the Canary Islands provided information and facilitated access to the parents. In addition, the Doctor Negrín University Hospital of Gran Canaria allocated a room and summoned the children and parents for follow-ups, guaranteeing the provision of the findings to participating families. Researchers expected students with hearing difficulties from diverse rural and urban settings and educational backgrounds reflecting the multicultural character of the population in the Canary Islands where participants lived.

The Psychopedagogical Team (PT) for schoolchildren with hearing difficulties in the Canary Islands assisted the investigators to access the schools where children with CIs or HAs studied. The criterion to take part in the study was that the teacher had to be currently teaching at least one student with CI or HA. Students who had additional cognitive, physical, and communicative disabilities possibly affecting different aspects related to the QoL-such as autism spectrum disorder, attention-deficit/hyperactivity disorder, or chronic illnesses-were excluded. All students had similar characteristics with regard to the range of age from 6 to 11 years $(M=8.58, S D=1.686)$; homogeneity of variance across groups in 3 tests: Raven's Progressive Matrices (Raven, 2000), Peabody Picture Vocabulary Test (Dunn \& Dunn, 2007), and Illinois Test of Psycholinguistic Abilities (ITPA) (Kirk, McCarthy, \& Kirk, 1968), and language background. They functioned satisfactorily in inclusive and regular primary education programs. No participants received compensation for their input.

The 2017-2018 population included data from 152 children with CIs $(n=89)$ against another group of children who used HAs $(\mathrm{n}=63)$.

The group of children with CIs fitted the following criteria:

(a) 42 were girls (47.2\%), and 47 were boys (52.8\%);

(b) 63 students attended inclusive schools with a deaf and hard-of-hearing program (70.8\%), and 26 students were enrolled in regular schools $(29.2 \%)$;

(c) the degree of hearing loss was $>90 \mathrm{~dB}$ in left ear for $69.7 \%$ of cases $(\mathrm{n}=62)$ and $66.3 \%$ in right ear $(\mathrm{n}=59)$;

(d) most children with hearing loss were diagnosed before 6 months of age $(\mathrm{n}=35 ; 39.3 \%)$, followed by those children diagnosed between 6 months and 1 year $(\mathrm{n}=24 ; 27 \%)$;

(e) 31 students were implanted by age from 1 to 2 years (41.3\%), and most children received bilateral implantation $(\mathrm{n}=67,84.8 \%)$;

(f) children's Raven's Progressive Matrices scores $(M=2.86, S D=1.041)$;

(g) students' Peabody Picture Vocabulary Test scores $(M=3.22, S D=1.447)$; and

(h) children's ITPA scores $(M=2.21, S D=0.789)$.

The detailed information for the children with HAs was described as follows:

(a) gender differences: 34 were boys (42\%), and 29 were girls (40.8\%);

(b) 48 students attended inclusive schools with a deaf and hard-of-hearing program (43.2\%), and 15 students were enrolled in regular schools (36.6\%);

(c) the degree of hearing loss was 40 to $70 \mathrm{~dB}$ in the right ear that was better than the left ear detected prior to 6 months of age: right ear $(\mathrm{n}=32,65.3 \%)$ and left ear $(\mathrm{n}=28,58.3 \%)$;

(d) fifteen students were fitted with HAs at 4 years of age $(53,8 \%)$; 
(e) children's Raven's Progressive Matrices scores $(M=3.17, S D=1.090)$;

(f) students' Peabody Picture Vocabulary Test scores $(M=2.58, S D=1.326)$; and

(g) children's ITPA $(M=2.79, S D=0.864)$.

The family participants were 89 parents of children with CIs and 63 parents of children with HAs. Parents were 31 to 40 years old $(M=77.33, S D=29.40)$, and mothers were between 41 to 50 years $(M=52.70, S D=42.12)$. Forty-six fathers of children with CIs had a Primary Education Diploma (51.7\%) and 38 mothers had a Primary Education Diploma (42.7\%); 62 fathers' labor status was categorized as working (69.7\%), and 51 mothers' labor status were working $(57.3 \%)$, and finally, 70 children used oral language as the preferred mode of communication in family (78.7\%). Thirty-seven fathers of children with HAs had a Primary Education Diploma (44.6\%), and 30 mothers had a Primary Education Diploma (44.1\%); 30 fathers' labor status were unemployed (52.6\%), and 39 mothers' labor status was categorized as working $(43.3 \%)$; finally, 49 children used oral language as the preferred mode of communication (in family) (41.2\%). Most parents of children with CIs or HAs attended to deaf programs $(M=84.40, S D=18.26)$.

\subsection{Instruments}

For the present study, the versions of $\mathrm{KINDL}^{\mathrm{R}}$ were used to measure HRQoL in children and parents:

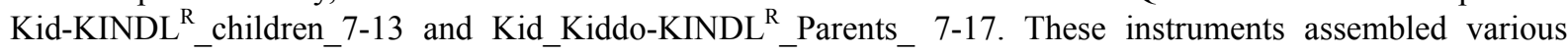

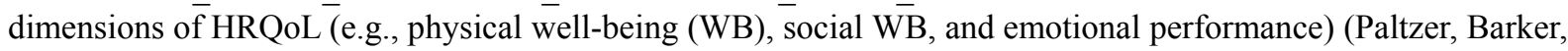
$\&$ Witt, 2013) and were a reliable source for newly developed survey questionnaires of similar domain structure (Devine et al., 2015).

Both $\mathrm{KINDL}^{\mathrm{R}}$ contained 24 questions distributed across 6 dimensions. The researchers collected the responses on a five-point Likert scale that categorized frequency on a range from " 1 = never" to " $5=$ always", and obtained the profile delivered by the instrument, a single overall score or average of HRQoL from the means of the 6 dimensions.

Additionally, children with CIs or HAs were asked to complete a battery of tests (e.g., Raven's Progressive Matrices) (Raven, 2000), Peabody Picture Vocabulary Test (Dunn \& Dunn, 2007), and ITPA (Kirk et al., 1968). Moreover, this study used a deliberate short socio-demographic characteristic questionnaire about child's setting, educational outcomes at school, gender, personal resources, number of siblings, sibling ordinal position, and health/clinical information. Parents assessed background factors (i.e., cochlear implant or hearing aid, setting, age, marital status, employment status, educational level, and type of school placement) and certain variables relevant to hearing loss (i.e., child's etiology of hearing loss, time of deafness diagnosis, parental hearing status, preferred mode of communication at home and by the child, parent courses in which parents participated, and number of weekly hours of logopedics).

\subsection{Procedure}

The current study included socio-demographic variables (age and gender), educational variables (school system and school environment), diversity variables (cause of deafness, age of deafness diagnosis, deafness in the family, and type of communication in the family), parents' proxy (father, mother, and sibling), and information sessions led by a qualified PT.

The school principal provided a room where researchers and teachers were involved in familiarization using the coding sheets while preparing the surveys and desk environment. When studying children younger than 8 years, a teacher read each item and asked the child to respond by circling the selected Kid-KINDL ${ }^{\mathrm{R}}$ children_7-13 item. The time spent completing the assignments in the research project varied to some degree for different children. Students did not complete all tests simultaneously as the children and parents in both groups fulfilled the HRQoL questionnaires.

All children with CIs or HAs attended inclusive and regular schools belonging to the educational system of the autonomous community of the Canary Islands. Data collection process took place over approximately 1 school calendar year. In the data reported here, there were no missing items. The transformed data were entered into a database by a researcher, and then another researcher double-checked data entry for all participants.

\subsection{Statistical Analyses}

The investigators converted HRQoL direct data collected from the $2 \mathrm{KINDL}^{\mathrm{R}}$ questionnaires into average items per dimension. All aspects and the overall scores of HRQoL were subjected to statistical analysis using the Statistical Package for Social Sciences (SPSS 16).

Researchers used Student's $t$-tests to compare the groups of children with CIs or HAs on each dimension of the 
Kid-KINDL $^{\mathrm{R}}$ _children_7-13 in the first question. Furthermore, the authors employed the one-way ANOVA to determine whether there was any statistically significant difference between the average total scores of the Kid-KINDL $^{\mathrm{R}}$ _children_7-13 for selected variables. After completing an ANOVA, a Scheffé post hoc test was applied because of different sample sizes, to find means that were significantly different from each other. Regarding the second research question, the authors performed the same procedure and type of analysis with the Kid_Kiddo-KINDL ${ }^{\mathrm{R}}$ _Parents_7-17.

\section{Results}

\subsection{Differences in HRQoL Dimensions of Children with CIs or HAs}

The researchers compared children's HRQoL mean dimensions and assessed children's socio-demographic characteristics, in order to address the first research question of the study. Table 1 displays the mean score of each dimension in the Kid-KINDLR_children_7-13 and shows that the Cronbach's alpha is highly reliable (0.976) (Figure 1).

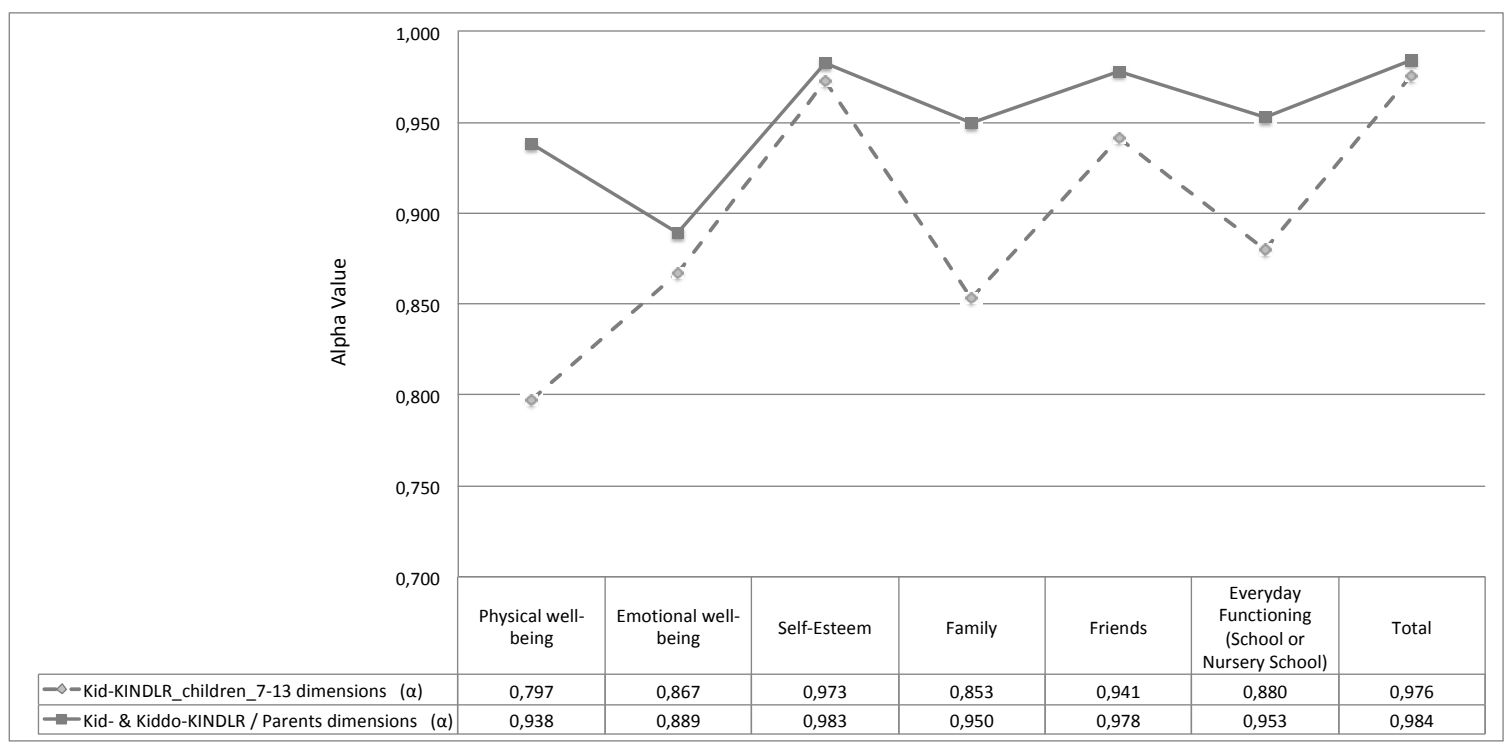

Figure 1. Cronbach's Alpha of Children with CIs or HAs in Kid-KINDL ${ }^{\mathrm{R}}$ children_7-13 dimensions

Moreover, it reveals that the mean values ranged from 18.80 to 71.51 , indicating that children considered the HRQoL positive, as presented in Figure 2. Self-Esteem received the highest scores $(M=71.51 ; S D=33.57)$, followed by Friends $(M=69.15 ; S D=31.18)$ and Everyday Functioning (School or Nursery School) in children with CIs $(M=61.12 ; S D=27.50)$. Emotional well-being obtained the lowest score $(M=18.80 ; S D=22.85)$, followed by Family $(M=19.20 ; S D=23.24)$ and Physical well-being in children with HAs $(M=19.92 ; S D$ $=23.88$ ). Student's $t$-test revealed a significant difference in all HRQoL dimensions between children with CIs or HAs. There were significant differences $(t=5.661, p<0.000)$ in the average HRQoL score of children with CIs or HAs so that children with CIs $(M=50.91 ; S D=22.00)$ displayed a better perception of HRQoL with regard to children with HAs $(M=26.83$; SD $=30.44)$. 
Table 1. Means, Standard Deviations, Minimum, Maximum, Student's $t$-test, and Cronbach's Alpha of Children with CIs or HAs in Kid-KINDL ${ }^{\mathrm{R}}$ _children_7-13 dimensions

\begin{tabular}{|c|c|c|c|c|c|}
\hline & Children with CIs/HAs & Mean & SD & $t$ & $\alpha$ \\
\hline \multirow{2}{*}{ Physical well-being } & CIs & 37.75 & 19.40 & \multirow{2}{*}{$5.067 * * *$} & \multirow{2}{*}{.797} \\
\hline & HAs & 19.92 & 23.88 & & \\
\hline \multirow{2}{*}{ Emotional well-being } & CIs & 33.25 & 19.59 & \multirow{2}{*}{$4.178^{* * *}$} & \multirow{2}{*}{.867} \\
\hline & HAs & 18.80 & 22.85 & & \\
\hline \multirow{2}{*}{ Self-Esteem } & CIs & 71.51 & 33.57 & \multirow{2}{*}{$5.630 * * *$} & \multirow{2}{*}{.973} \\
\hline & HAs & 36.82 & 42.28 & & \\
\hline \multirow{2}{*}{ Family } & CIs & 32.69 & 19.26 & \multirow{2}{*}{$3.901 * * *$} & \multirow{2}{*}{.853} \\
\hline & HAs & 19.20 & 23.24 & & \\
\hline \multirow{2}{*}{ Friends } & CIs & 69.15 & 31.18 & \multirow{2}{*}{$5.871 * * *$} & \multirow{2}{*}{.941} \\
\hline & HAs & 35.00 & 40.51 & & \\
\hline \multirow{2}{*}{ Everyday Functioning (School or Nursery School) } & CIs & 61.12 & 27.50 & \multirow{2}{*}{$5.822 * * *$} & \multirow{2}{*}{.880} \\
\hline & HAs & 31.26 & 35.67 & & \\
\hline \multirow{2}{*}{ Total } & CIs & 50.91 & 22.00 & \multirow{2}{*}{$5.661 * * *$} & \multirow{2}{*}{.976} \\
\hline & HAs & 26.83 & 30.44 & & \\
\hline
\end{tabular}

Note. Children with CIs ( $\mathrm{n}=89 ; 47$ boys, 42 girls); children with HAs ( $\mathrm{n}=63 ; 34$ boys, 29 girls); $\alpha=$ Cronbach's alpha coefficients; $* * * p<0.001$.

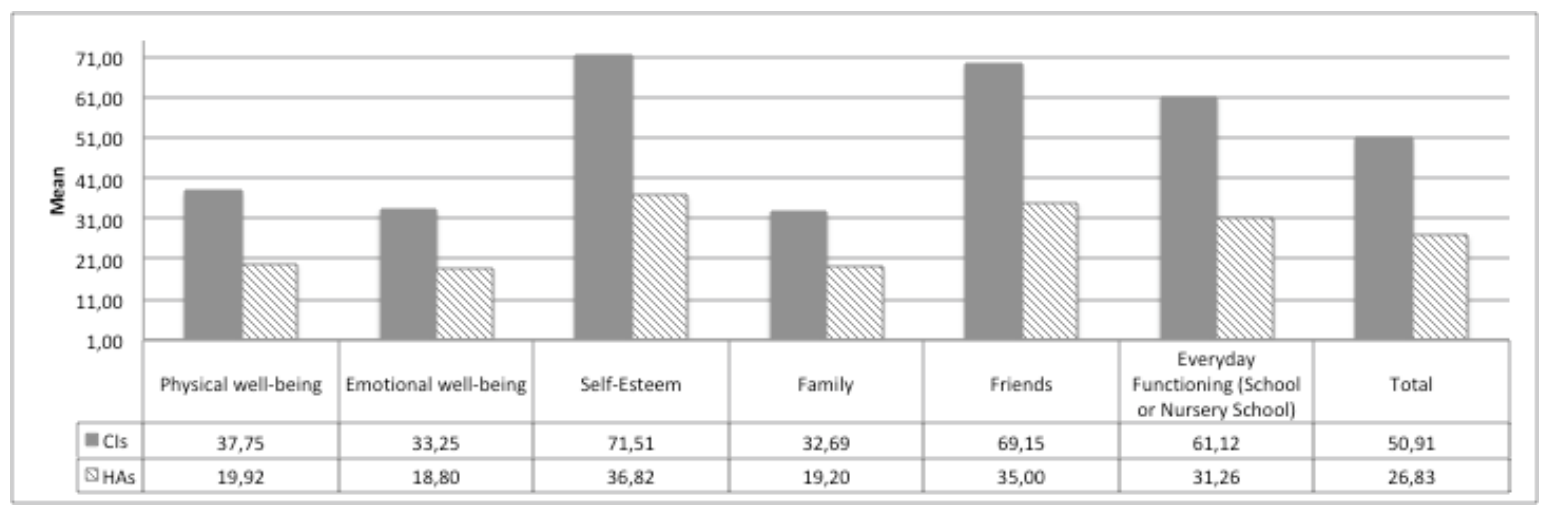

Figure 2. Means of children with CIs or HAs in Kid-KINDL ${ }^{\mathrm{R}}$ children_7-13 dimensions

\subsection{Differences in Socio-Demographic Characteristics of Children with CIs or HAs}

Table 2 presents statistically significant differences between levels of socio-demographic characteristics for each group of children with CIs or HAs in the overall mean HRQoL score. Moreover, Table 2 shows statistically significant differences in the overall mean HRQoL score of children with CIs or HAs.

There were no statistically significant differences between the groups of children with CIs or HAs concerning Gender and Raven's Progressive Matrices. In addition, there were no statistically significant differences in Last semester marks awarded, Last course marks awarded, Personal resources, Number of siblings, Sibling ordinal position, Left ear hearing loss, ITPA, and Peabody Picture Vocabulary Test in children with HAs. Furthermore, there were no statistically significant differences in Setting, Last semester marks awarded, Last course marks awarded, Sibling ordinal position, Left ear hearing loss, and Peabody Picture Vocabulary Test in children with CIs. However, this group of children had the highest number of significant inner characteristic differences.

There were statistically significant differences between children with HAs in Setting (i.e., provinces of Tenerife and Gran Canaria) $(t=3.230, p<0.004)$. Moreover, there were statistically significant differences between children with CIs or HAs in Setting $(t=2.921, p<0.010)$.

A one-way ANOVA, followed by the Scheffé post hoc test $(-34.06, p<0.004)$, revealed that the scores of children with Outstanding marks $(N=11, M=58.56, S D=4.31)$ were higher in $\operatorname{HRQoL}(F(4,147)=3.669, p<0.010)$ than those children with Insufficient marks $(N=33, M=24.49, S D=29.56)$ in Last semester marks awarded. Similar results occurred with the values obtained in the Last course marks awarded where those children with better marks 
displayed better HRQoL $(F(4,147)=4.219, p<0.003)$. Post hoc comparisons showed statistically significant differences between children with Insufficient marks and children with other marks (Good: $-20.50, p<0.029$; Remarkable: $-19.49, p<0.043$, and Outstanding: $-33.45, p<0.005$ ).

Children with CIs had statistically significant differences according to the Personal Resource $(F(3)=4.109, p<$ 0.009)), attaining higher scores than those children who have 2 resources (i.e., Speech and language therapist (SLT) and Spanish sign language teacher (SSLT) (Scheffé: $51.20, p<0.006$ ). The study also indicated that children with CIs had statistically significant differences in the Number of siblings $(F(4)=5.999, p<0.0021)$. Post hoc analysis revealed a significant difference between 1 and 4 siblings (Scheffé: 50.22, $p<0.012$ ), obtaining a higher average score in HRQoL those children who have only 1 sibling $(N=31, M=57.31, S D=13.93)$ compared with those children who have 4 siblings $(N=4, M=7.98, S D=14.16)$.

Furthermore, children with CIs or HAs had statistically significant differences in Number of siblings $(F(4,147)=$ $2.954, p<0.05)$ and Sibling ordinal position $(F(3,148)=3.557, p<0.010)$. In this demographic characteristic, the first sibling had the highest mean $(N=98, M=44.92, S D=26.88)$. A post hoc indicated that there was indeed a significant difference between the first and the third sibling (Scheffé: $26.40, p<0.034$ ) in favour of those who were first-borns.

There were statistically significant differences between children with CIs or HAs in Left ear hearing loss $(F(2,149)$ $=3.425, p<0.05$ ). Post hoc testing indicated a significant difference between children with profound hearing loss and severe-medium hearing loss (Scheffé: $-5.59, p<0.029$ ).

Children with CIs or HAs had statistically significant differences in Age at diagnosis of hearing loss $(F(4,147)=$ 2.540, $p<0.042$ ). Post hoc indicated that children diagnosed between 1 to 2 years had better HRQoL (Scheffé: $23.52, p<0.027)$.

Children with CIs were significantly different in the ITPA test scores $(F(3)=3.105, p<0.033)$. Children who scored moderate in ITPA had higher HRQoL in comparison to those who scored low (Scheffé: $-17.70, p<.033$ ). Children with CIs or HAs who scored differently in ITPA had a distinct average mean HRQoL score $(F(3,102)=$ $4.119, p<0.010$ ) with higher average values in those children who scored higher in ITPA.

Finally, children with CIs or HAs had statistically significant differences in the Peabody Picture Vocabulary Test scores $(F(5,122)=2.432, p<0.010)$. Post hoc Scheffé probing analysis revealed that children with moderate low scores differed from those with low medium scores in favour of the latter (Scheffé: $-17.70, p<0.033$ ). 
Table 2. Differences in HRQoL between socio-demographic characteristics of children with CIs or HAs

\begin{tabular}{|c|c|c|c|}
\hline $\begin{array}{l}\text { Socio-Demographic Characteristics } \\
\text { (Levels) }\end{array}$ & $\begin{array}{l}\text { Total HRQoL Children } \\
\text { with CIs } \\
\begin{array}{c}n=89 \\
F\end{array}\end{array}$ & $\begin{array}{l}\text { Total HRQoL Children } \\
\text { with HAs } \\
\begin{array}{c}n=63 \\
t\end{array}\end{array}$ & $\begin{array}{c}\text { Total HRQoL } \\
\text { Children with CIs } \\
\text { or HAs } \\
N=152 \\
t \text { or } F \\
\end{array}$ \\
\hline $\begin{array}{l}\text { Province } \\
\text { (Tenerife/Gran Canaria) }\end{array}$ & NS & $3.230 * *$ & $2.921 * *$ \\
\hline $\begin{array}{l}\text { Last semester marks awarded } \\
\text { (Insuf./Profic./Good/Remark./Ousts.)+ }\end{array}$ & NS & NS & $3.669 * *$ \\
\hline $\begin{array}{l}\text { Last course marks awarded: } \\
\text { (Insuf./Profic./Good/Remark./Ousts.)+ }\end{array}$ & NS & NS & $4.219 * * *$ \\
\hline $\begin{array}{l}\text { Personal Resources } \\
\text { (SLT/SSLT/SLT and SSLT/Unsupported) ++ }\end{array}$ & $4.109^{* *}$ & NS & NS \\
\hline $\begin{array}{l}\text { Number of siblings } \\
(0 / 1 / 2 / 3 / 4)\end{array}$ & $5.999 * * *$ & NS & $2.954 *$ \\
\hline $\begin{array}{l}\text { Sibling ordinal position } \\
\left(1^{\circ} / 2^{\circ} / 3^{\circ} / 4^{\circ}\right)\end{array}$ & NS & NS & $3.557 * *$ \\
\hline $\begin{array}{l}\text { Left ear hearing loss } \\
\text { (Mild, Severe-Medium, Deep) }\end{array}$ & NS & NS & $3.425^{*}$ \\
\hline $\begin{array}{l}\text { Age at diagnosis of hearing loss } \\
\text { (Before } 6 \text { months/ } 6 \text { months-1 year/1-2 years/2-3 years/4 year or } \\
\text { later) }\end{array}$ & NS & NS & $2.540^{*}$ \\
\hline $\begin{array}{l}\text { ITPA } \\
\text { (Very low/Moderate low/Medium/Moderate high) }\end{array}$ & $3.105^{*}$ & NS & $4.119^{* *}$ \\
\hline $\begin{array}{l}\text { Peabody } \\
\text { (Very low/Moderate low/Low medium/High medium/Moderate } \\
\text { high/Very high) }\end{array}$ & NS & NS & $2.432 *$ \\
\hline
\end{tabular}

\subsection{Parents' Comparisons in HRQoL Dimensions}

The investigators compared the parents' HRQoL mean dimensions and assessed family background factors to address the second research question. Table 3 displays the mean score of each Kid_Kiddo-KINDL ${ }^{\mathrm{R}}$ Parents_7-17 dimension, and the Cronbach's alpha (0.984) indicated a higher internal consistency or reliability of the data set. All alpha scores were high in each dimension (e.g., Friends had the highest alpha) (0.978), and Emotional well-being had the lowest alpha (0.889). Student's $t$-test indicated statistically significant differences in the overall mean HRQoL score of parents of children with CIs or HAs, as well as in each HRQoL dimension $(t=5.661, p<$ $0.001)$. Parents of children with CIs had a higher overall mean HRQoL score $(M=73.32, S D=31.68)$ than parents of children with HAs $(M=38.64, S D=43.84)$ (Figure 3). 
Table 3. Means, standard deviations, minimum, maximum, student's $t$-test, and Cronbach's Alpha of parents of children with CIs or HAs in Kid- \& Kiddo-KINDL ${ }^{\mathrm{R} /}$ Parents dimensions

\begin{tabular}{|c|c|c|c|c|c|}
\hline $\begin{array}{l}\text { Kid- \& Kiddo-KINDL }{ }^{\mathrm{R}} / \text { Parents } \\
\text { Dimensions }\end{array}$ & $\begin{array}{c}\text { Parents of children with } \\
\text { CIs/HAs }\end{array}$ & Mean & $S D$ & $t$ & $\alpha$ \\
\hline \multirow{2}{*}{ Physical well-being } & $C I s$ & 37.75 & 19.40 & \multirow{2}{*}{$5.067 * * *$} & \multirow[t]{2}{*}{.938} \\
\hline & $H A s$ & 19.92 & 23.88 & & \\
\hline \multirow{2}{*}{ Emotional well-being } & CIs & 39.26 & 30.23 & \multirow{2}{*}{$4.898 * * *$} & \multirow[t]{2}{*}{.889} \\
\hline & $H A s$ & 15.39 & 28.68 & & \\
\hline \multirow{2}{*}{ Self-Esteem } & $C I s$ & 52.30 & 40.09 & \multirow{2}{*}{$6.109 * * *$} & \multirow[t]{2}{*}{.983} \\
\hline & HAs & 15.79 & 30.11 & & \\
\hline \multirow{2}{*}{ Family } & CIs & 22.97 & 20.54 & \multirow{2}{*}{$2.860 * *$} & \multirow[t]{2}{*}{.950} \\
\hline & $H A s$ & 12.22 & 25.75 & & \\
\hline \multirow{2}{*}{ Friends } & $C I s$ & 53.98 & 40.76 & \multirow{2}{*}{$5.329 * * *$} & \multirow[t]{2}{*}{.978} \\
\hline & HAs & 19.84 & 36.13 & & \\
\hline \multirow{2}{*}{ Everyday Functioning (School or Nursery School) } & CIs & 45.39 & 38.04 & \multirow{2}{*}{$5.377 * * *$} & \multirow[t]{2}{*}{.953} \\
\hline & HAs & 15.00 & 28.24 & & \\
\hline \multirow{2}{*}{ Overall } & $C I s$ & 73.32 & 31.68 & \multirow{2}{*}{$5.661 * * *$} & \multirow{2}{*}{.984} \\
\hline & $H A s$ & 38.64 & 43.84 & & \\
\hline
\end{tabular}

Note. Parents of children with CIs ( $\mathrm{n}=89 ; 21$ fathers, 66 mothers, y 2 proxies). Parents of children with HAs (n $=63 ; 10$ fathers, 53 mothers); $\alpha=$ Cronbach's alpha coefficients; $* * p<0.010 ; * * * p<0.001$.

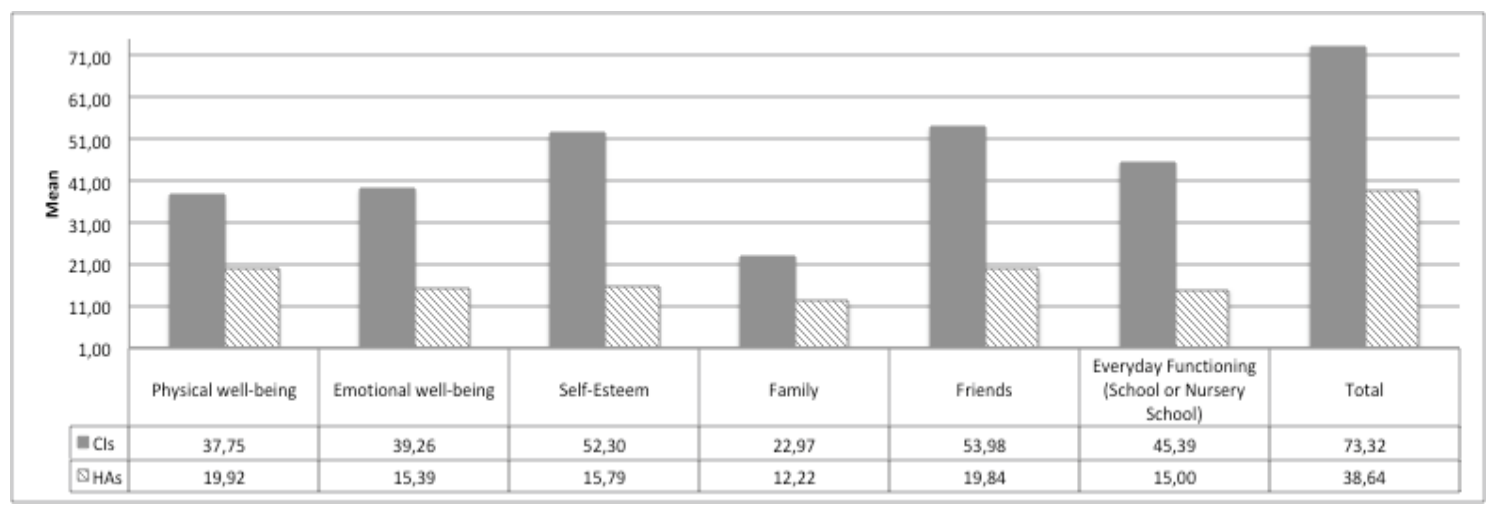

Figure 3. Means of parents of children with CIs or HAs in Kid- \& Kiddo-KINDL ${ }^{\mathrm{R}}$ Parents dimensions

\subsection{Comparing Differences in Family Background Factors}

Table 4 presents statistically significant differences between levels of background factors for each group of parents of children with CIs or HAs in the overall mean HRQoL score.

There were no statistically significant differences in HRQoL between parents of children with CIs or HAs on the following background factors: Gender, Marital status, Educational level, Type of school placement, Child's etiology of hearing loss, Time of deafness diagnosis, Parental hearing status, and Number of weekly hours of logopedics.

In addition, there were no statistically significant differences within parents of children with CIs or HAs concerning preferred mode of communication at home and by the child. Furthermore, there were no statistically significant differences in HRQoL of parents of children with CIs keeping in mind the following background factors: Setting, Father's Age, Mother's Age, Fathers' employment status, and Preferred mode of communication at home and by the child. Moreover, there was no statistically significant difference in HRQoL of parents of children with HAs regarding parent courses in which they participated. However, this group of parents had the highest number of significant inner background differences.

There were statistically significant differences between parents of children with CIs or HAs regarding Setting $(t(150)=2.921, p<0.004)$. Besides, a one-way ANOVA, followed by the Scheffé post hoc test $(p<0.05)$, revealed that there were statistically significant differences between parents of children with CIs or HAs concerning 
Father's Age $(F(3,148)=3.904, p<0.010)$. Post hoc test revealed significant differences between ages 31 to 40 and 41 to 50 (Scheffé: 44.83, $p<0.040$ ) with higher HRQoL values in the case of younger parents of children with HAs. Similarly, there were statistically significant differences between parents of children with CIs or HAs regarding the Mother's Age $(F(3,148)=5.610, p<0.001)$. A post hoc analysis revealed that mother's age between 31 to 40 years obtained higher mean $(M=77.33, S D=29.40)$ between parents of children with CIs or HAs (Scheffé: $24.55, p<0.010$ ) and between parents of children with HAs (Scheffé: 49.34, $p<0.007$ ).

There were statistically significant differences between parents of children with CIs or HAs concerning Fathers' employment status $(F(2,149)=10.270, p<.000)$. Post hoc test analysis indicated that employed parents of children with CIs or HAs $(M=68.45, S D=37.05)$ had significantly higher HRQoL than other unemployed or retired parents (Scheffé: $-17.10, p<0.027$ ).

There were statistically significant differences between parents of children with CIs or HAs concerning the Preferred mode of communication at home and by the child $(F(2,149)=3.354, p<0.038)$. Post hoc test analysis stated that oral communication $(M=61.99, S D=40.66)$ was the preferred mode of communication compared to other types (sign or bilingual).

Finally, there were statistically significant differences between parents of children with CIs or HAs who had engaged on hearing loss learning courses compared with those who had not taken courses $(t(77)=2.033, p<$ 0.045), perceiving parents of children with CIs better HRQoL.

Table 4. Differences in HRQoL between background factors of parents of children with CIs or HAs

\begin{tabular}{|c|c|c|c|}
\hline $\begin{array}{l}\text { Family Background Factors } \\
\text { (Levels) }\end{array}$ & $\begin{array}{c}\text { Parents of Children } \\
\text { with } \\
\text { CIs } \\
n=89 \\
t\end{array}$ & $\begin{array}{c}\text { Parents of Children } \\
\text { with } \\
\text { HAs } \\
n=63 \\
t \text { or } F\end{array}$ & $\begin{array}{l}\text { Total HRQoL } \\
\text { Parents of Children with CIs or } \\
\text { HAs } \\
\begin{array}{c}N=152 \\
t \text { or } F\end{array}\end{array}$ \\
\hline $\begin{array}{l}\text { Setting } \\
\text { (Tenerife/Gran Canaria) }\end{array}$ & NS & $3.230 * *$ & $2.921 * *$ \\
\hline $\begin{array}{l}\text { Father's Age } \\
(20-30 / 31-40 / 41-50 / 50 \text { or older })\end{array}$ & NS & $3.999^{*}$ & $3.904 * *$ \\
\hline $\begin{array}{l}\text { Mother's Age } \\
(20-30 / 31-40 / 41-50 / 50 \text { or older })\end{array}$ & NS & $4.646 * *$ & $5,610 * * *$ \\
\hline $\begin{array}{l}\text { Fathers' employment } \\
\text { (Unemployed/Employed/Retired) }\end{array}$ & NS & $3.350 *$ & $10.270 * * *$ \\
\hline $\begin{array}{l}\text { Preferred mode of communication at home and by the } \\
\text { child } \\
\text { (Sign/Oral/Bilingual) }\end{array}$ & NS & NS & $3.354 *$ \\
\hline $\begin{array}{l}\text { Parent courses in which parents participated } \\
(\text { Yes/No) }\end{array}$ & $2.230 *$ & NS & $2.033 *$ \\
\hline
\end{tabular}

Note. ${ }^{*} p<0.05, * * p<0.010, * * * p<0.001 ;$ Parents of children with CIs $(N=89 ; 21$ fathers, 66 mothers, and 2 proxies); Parents of children with HAs ( $N=63 ; 10$ fathers and 53 mothers); NS, not significant $(p>0.05)$.

\section{Discussion}

\subsection{Understanding Children's Views Regarding HRQoL}

The first question of the current study examined HRQoL dimensions among two groups of children with CIs or HAs. Results indicated that schoolchildren with CIs or HAs responded differently to the Kid-KINDLR_children_7-13 dimensions, according to the discrepant perceptions of HRQoL. Apart from the item "I felt strong and full of energy," children with CIs or HAs differed in the rest of the 24 items assessed by the questionnaire. Thus, the findings of the present study contradicted somewhat to that of Meserole et al.'s conclusion regarding the comparable HRQoL experience of CI recipients and hearing peers. In this respect, it would be thought-provoking to distinguish whether dissimilarities in HRQoL students' ratings developed from differences in one questionnaire item as some researchers reported (Warner-Czyz et al., 2011), although later studies have indicated that differences might be associated to other causes (i.e., reading comprehension, speech intelligibility, or risk of fatigue) (Hornsby et al., 2014; Freeman et al., 2017). 
The first aim of the current study also assessed children's socio-demographic characteristics. Lack of statistical significance between HRQoL dimensions and some socio-demographic variables could reflect the homogeneity of the study population due to low standard deviations of the research variables. However, the variable Setting (i.e., geographical and administrative provinces of Gran Canaria and Tenerife) maintained meaningful statistical differences between children with CIs or HAs on the mean dimensions. The analysis showed that provinces played an essential role in the HRQoL dimensions for the Canary autonomous community. The researchers estimated that children with CIs who were attended at the hospital in Gran Canaria had similar socio-demographic characteristics, while the socio-demographic variables were different for children with HAs.

The authors noticed meaningful differences between children with CIs or HAs in some items of the Friends dimension. The researchers attributed these differences to the lack of peer friends who could improve the social distance of both groups of children. This supposition coincided with findings previously declared by some researchers (Punch \& Hyde, 2011, p. 488).

The school environment differed between children with CIs or HAs when examining the HRQoL mean dimensions, except for the domain Physical well-being. However, this dimension was significantly different between children with CIs. These findings need further investigation to know whether younger children would score higher than older ones in this dimension as reported by other researchers (Pardo-Guijarro et al., 2015). Put together, the current study validated the importance of the school environment (i.e., itinerant teachers, teachers, school counsellors, and school psychologists) for the social and emotional development of children with CIs as it was reported in past research (Hintermair, 2011; Kumar et al., 2015). Contrary to the opinion of Rekkedal (2012), children with CIs or HAs did not reveal that users' hearing devices predisposed their attitude to quality of life. Together, these findings suggested that children with CIs noticed HRQoL differently and showed a better perception of HRQoL concerning children with HAs. Additionally, this finding was consistent with other studies that reported the efforts faced by children with CIs on the Family dimension (Loy et al., 2010).

\subsection{Parents' Perceptions of HRQoL: Groups Similarities and Differences}

Derived from the second study question, parents of children with CIs or HAs had different HRQoL perceptions. There were statistically significant differences between parents of children with CIs or HAs regarding the variable Setting. Moreover, parents of children with CIs had a higher mean HRQoL score than parents of children with HAs. Likewise, in a previous study, Kumar et al. (2015) reported that parents of children and adolescents with CIs rated HRQoL positively across all domains.

The current study mirrored the finding of parents rating family's geographical and administrative residence as one of the most crucial aspects of HRQoL in young children. Parents of children with CIs overestimated HRQoL dimensions because they were supposedly more in touch with the Pediatric Audiology service at the Hospital of Gran Canaria. Nevertheless, this result was opposite to other findings that showed that parents underrated their children's HRQoL (Razafimahefa-Raoelina et al., 2016).

Although oral communication was the preferred mode of communication of children at home compared to other types of communication (sign or bilingual), there were significant differences between the two groups of parents. This explanation supported researchers' assertion that one factor of cognitive maturation in children's communication skills was early cochlear implantation (Huttunen et al., 2009). Authors argue that parents of children with HAs had their children scarcely exposed to sign language or communication strategies with peers, as other researchers have reported (Most, Shina-August, \& Meilijson, 2010).

Three parenting background factors (i.e., age, socioeconomic status, and learning) compelled researchers to examine how parents experienced and challenged relationships with children fitted with HAs (Rotsika et al., 2011; Sarant \& Garrard, 2014; Veland et al., 2014). These significant factors increased the presence of differences between all parents and enhanced their need for practice in inclusive education. No doubt, the variable parents' socioeconomic status is explicitly connected to effective management strategies (i.e., parent-audiologist partnership) that had been demanding in research synthesis (Muñoz et al., 2016).

\subsection{Study Limitations and Recommendations for Further Research}

This study had certain research limitations. The current study selected a child population segmented by the primary school grade with similar levels of cognitive and linguistic development. Future studies could examine changes in HRQoL dimensions in children following the transition to upper grades and select new predictors (e.g., fatigue ratings, school achievement, and inclusive school cultures) of better HRQoL mean dimensions. The researchers underlined that children with CIs or HAs interacted with regular school peers, whereas those in inclusive schools cooperated with peers and their SLT, signifying in the school environment, the probability of a confounding 
variable.

There are several recommendations for research and practice that arise from the current study. Large-sample, well-designed, prospective cohort studies to provide stronger scientific evidence, should be performed in the future. Consistent with findings from Musyoka, Gentry, \& Meek (2017), the investigators encouraged the design and validation of a KINDL ${ }^{\mathrm{R}}$ questionnaire for teachers, adapting the one requested for parents, as other researchers suggested (Sakiz et al., 2015). In the context of research HRQoL on parents of children with CIs or HAs, future research should examine additional parents' social cognitive aspects for comparative purposes (Hintermair et al., 2017). Moreover, the involvement of parents in child language acquisition was evident for children's development and well-being (Bruin, 2018). Provided the heterogeneity of the children with CIs or HAs population and the different assumed causes of deafness, the Kid-KINDLR_children_7-13 can be used to compare HRQoL across disease etiologies (e.g., genetic loss versus unexplained deafness), associate outcomes of children with CIs or HAs across inclusive and regular schools, and analyze the benefits of simultaneous versus sequential bilateral cochlear implantation. Thus, one should work through complex experiments to give better answers to families, schoolteachers, and PT members, as other researchers have previously reported (English, 2010; Muñoz et al., 2016). Furthermore, one must analyze other socio-demographic variables that foster implanted children's home communication and activities, as prior researchers have studied (Warner et al., 2011). Hence, it will be plausible to know if bilateral cochlear implantation will bring added value in HRQoL to children and their families.

Investigators considered it reasonable to associate the HRQoL of implanted children with results of language and communication growth in infants without additional needs (Edwards et al., 2012; Rekkedal, 2012). In the current study, the PTs assisted the children to answer the demographic questionnaires and aid their parents in completing the socio-demographic survey. Overall, the researchers encouraged a line of research on parent mentoring. For example, parents trained by PTs should provide what is necessary for understanding and responding to the children's multiple disabilities and hearing-related topics (Narr \& Kemmery, 2015).

\section{Conclusion}

The current study provided a valuable contribution to our understanding of children with hearing loss and their parents. Children with CIs and their parents displayed a perception of better HRQoL than children with HAs and their parents. These findings added to the existing knowledge about the benefits of CIs for children with hearing loss. Parents of children with CIs noted the significance of social and emotional development as a marker of well-being in their children's lives.

\section{Acknowledgements}

The authors wish to thank all the children and parents who participated in this study for their time and collaboration. This research was funded by CajaCanarias Foundation, grant number CSOCSEDO3. Plaza del patriotismo 1, 2a planta. City code: 38002. Santa Cruz de Tenerife (Spain). Phone: 922471100. Email: info@cajacanarias.com.

\section{References}

Berger, J.-L., \& Karabenick, S. A. (2016). Construct Validity of Self-Reported Metacognitive Learning Strategies. Educational Assessment, 21(1), 19-33. https://doi.org/10.1080/10627197.2015.1127751

Bland, J. M., \& Altman, D. G. (1986). Statistical methods for assessing agreement between two methods of clinical measurement. Lancet, 1, 307-310. https://doi.org/10.1016/S0140-6736(86)90837-8

Bruin, M. (2018). Parental Involvement in Children's Learning: The Case of Cochlear Implantation-Parents as Educators? Scandinavian Journal of Educational Research, 62(4), 601-616. https://doi.org/10.1080/00313831.2016.1258728

Devine, J., Otto, C., Rose, M., Barthel, D., Fischer, F., Mühlan, H., ... Ravens-Sieberer, U. (2015). A new computerized adaptive test advancing the measurement of health-related Quality of life (HRQoL) in children: the Kids-CAT. Quality of Life Research: an international journal of quality of life aspects of treatment, care and rehabilitation, 24(4), 871-884. https://doi.org/10.1007/s11136-014-0812-7

Duarte. I., Santos, C. C., Rego, G., \& Nunes, R. (2014). Health-related quality of life in children and adolescents with cochlear implants: Self and proxy reports. Acta Oto-Laryngologica, 134, 881-889. https://doi.org/10.3109/00016489.2014.930968

Dunn, L. M., \& Dunn, D. M. (2007). The Peabody Picture Vocabulary Test (4th ed.). Minneapolis, MN: NCS Pearson. https://doi.org/10.1037/t15144-000

Edwards, L., Hill, T., \& Mahon, M. (2012). Quality of life in children and adolescents with cochlear implants 
and additional needs. International Journal of Pediatric Otorhinolaryngology, 76(6), 851-857. https://doi.org/10.1016/j.ijporl.2012.02.057

English, K. (2010). Counseling Challenges and Strategies for Cochlear Implant Specialists. Deafness \& Education International, 12(3), 130-134. https://doi.org/10.1179/146431510X12626982043886

Freeman, V., Pisoni, D. B., Kronenberger, W. G., \& Castellanos, I. (2017). Speech intelligibility and psychosocial functioning in deaf children and teens with cochlear implants. The Journal of Deaf Studies and Deaf Education, 22, 278-289. https://doi.org/10.1093/deafed/enx001

Giavarina, D. (2015). Understanding Bland Altman analysis. Biochemia Medica, 25(2), 141-145. https://doi.org/10.11613/BM.2015.015

Haukedal, C. L., Lyxell, B., \& Wie, O. B. (2019). Health-Related Quality of Life With Cochlear Implants: The Children's Perspective. Ear Hear. https://doi.org/10.1097/AUD.0000000000000761

Haukedal, C. L., von Koss, J., Lyxell, B., \& Wie, O. B. (2018). Parents' Perception of Health-Related Quality of Life in Children with Cochlear Implants: The Impact of Language Skills and Hearing. J Speech Lang Hear Res., 61(8), 2084-2098. https://doi.org/10.1044/2018_JSLHR-H-17-0278

Hintermair, M. (2011). Health-related quality of life and classroom participation of deaf and hard-of-hearing students in general schools. The Journal of Deaf Studies and Deaf Education, 16(2), 254-271. https://doi.org/10.1093/deafed/enq045

Hintermair, M., Sarimski, K., \& Lang, M. (2017). Preliminary Evidence Assessing Social-Emotional Competences in Deaf and Hard of Hearing Infants and Toddlers Using a New Parent Questionnaire. The Journal of Deaf Studies and Deaf Education, 22(2), 143-154. https://doi.org/10.1093/deafed/enw070

Hoffman, M. F., Cejas, I., \& Quittner, A. L. (2018). Health-Related Quality of Life Instruments for Children with Cochlear Implants: Development of Child and Parent-Proxy Measures. Ear \& Hear, 40(3), 592-604. https://doi.org/10.1097/AUD.0000000000000631

Hornsby, B. W. Y., Werfel, K., Camarata, S., \& Bess, F. H. (2014). Subjective Fatigue in Children with Hearing Loss: Some Preliminary Findings. Am $J$ Audiol., 23(1), 129-134. https://doi.org/10.1044/1059-0889(2013/13-0017)

Huttunen, K., Rimmanen, S., Vikman, S., Virokannas, N., Sorri, M., Archbold, S., \& Lutman, M. E. (2009). Parents' views on the quality of life of their children 2-3 years after cochlear implantation. International Journal of Pediatric Otorhinolaryngology, 73, 1786-1794. https://doi.org/10.1016/j.ijporl.2009.09.038

Jardine, J., Glinianaia, S. V., McConachie, H., Embleton, N. D., \& Rankin, J. (2014). Self-Reported Quality of Life of Young Children with Conditions from Early Infancy: A Systematic Review. Pediatrics, 134(4), e1129-e1148. https://doi.org/10.1542/peds.2014-0352

Karimi, M., Brazier, J. (2016). Health, Health-Related Quality of Life, and Quality of Life: What is the Difference? Pharmaeconomics, 34(7), 645-649. https://doi.org/10.1007/s40273-016-0389-9

Kirk, S. A., McCarthy, J. J., \& Kirk, W. D. (1968). Illinois Test of Psycholinguistic Abilities. Urbana: University of Illinois Press.

Kumar, R., Warner-Czyz, A., Silver, C. H., Loy, B., \& Tobey, E. (2015). American parent perspectives on quality of life in pediatric cochlear implant recipients. Ear \& Hear, 36(2), 269-278. https://doi.org/10.1097/AUD.0000000000000108

Lee, P. H., Chang, L. I., \& Ravens-Sieberer, U. (2008). Psychometric evaluation of the Taiwanese version of the Kiddo-KINDL generic children's health-related quality of life instrument. Quality of Life Research, 17(4), 603-611. https://doi.org/10.1007/s11136-008-9328-3

Loy, B., Warner-Czyz, A. D., Tong, L., Tobey, E. A., \& Roland, P. S. (2010). The children speak: An examination of the quality of life of pediatric cochlear implant users. Otolaryngology-Head and Neck Surgery, 142(2), 247-253. https://doi.org/10.1016/j.otohns.2009.10.045

Martin, D., Bat-Chava, Y., Lalwani, A., \& Waltzman, S. B. (2011). Peer Relationships of Deaf Children with Cochlear Implants: Predictors of Peer Entry and Peer Interaction Success. The Journal of Deaf Studies and Deaf Education, 16(1), 108-120. https://doi.org/10.1093/deafed/enq037

Meserole, R. L., Carson, Ch. M., Riley, A. W., Wang, N.-Y., Quittner, A. L., Eisenberg, L. S., ... Niparko, J. K. (2014). Assessment of health-related quality of life 6 years after childhood cochlear implantation. Quality of 
Life Research, 23(2), 719-731. https://doi.org/10.1007/s11136-013-0509-3

Michael, R, Attias, J., \& Raveh, E. (2019). Cochlear Implantation and Social-Emotional Functioning of Children with Hearing Loss. The Journal of Deaf Studies and Deaf Education, 24(1), 25-31. https://doi.org/10.1093/deafed/eny034

Most, T., Shina-August, E., \& Meilijson, S. (2010). Pragmatic Abilities of Children With Hearing Loss Using Cochlear Implants or Hearing Aids Compared to Hearing Children. The Journal of Deaf Studies and Deaf Education, 15(4), 422-437. https://doi.org/10.1093/deafed/enq032

Muñoz, K., Rusk, S. E. P., Nelson, L., Preston, E., White, K. R., Barrett, T. S., \& Twohig, M. P. (2016). Pediatric Hearing Aid Management: Parent-Reported Needs for Learning Support. Ear \& Hearing, 37(6), 703-709. https://doi.org/10.1097/AUD.0000000000000338

Musyoka, M. M., Gentry, M. A., \& Meek, D. R. (2017). Perceptions of Teachers' Preparedness to Teach Deaf and Hard of Hearing Students with Additional Disabilities: A Qualitative Case Study. Journal of Developmental and Physical Disabilities, 29(5), 827-848. https://doi.org/10.1007/s10882-017-9555-z

Narr, R. F., \& Kemmery, M. (2015). The Nature of Parent Support Provided by Parent Mentors for Families with Deaf/Hard-of-Hearing Children: Voices From the Start. The Journal of Deaf Studies and Deaf Education, 20(1), 67-74. https://doi.org/10.1093/deafed/enu029

Navarro, J. S., \& Merino, C. (2016). Estructura Latente del Kiddo-Kindl en una Muestra Peruana. LIBERABIT: Lima (Perú), 22(1), 77-89. https://doi.org/10.24265/liberabit.2016.v22n1.07

Neumann, S., Salm, S., Rietz, Ch., \& Stenneken, P. (2017). The German Focus on the Outcomes of Communication Under Six (FOCUS-G): Reliability and Validity of a Novel Assessment of Communicative Participation. Journal of Speech, Language, and Hearing Research, 60, 675-681. https://doi.org/10.1044/2016_JSLHR-L-15-0219

Paltzer, J., Barker, E., \& Witt, W. P. (2013). Measuring the health-related quality of life (HRQoL) of young children in resource-limited settings: a review of existing measures. Quality Life Research, 22, 1177-1187. https://doi.org/10.1007/s11136-012-0260-1

Pardo-Guijarro, M. J., Martínez-Andrés, M., Notario-Pacheco, B., Solera-Martínez, Sánchez-López, M., \& Martinez-Vizcaino, V. (2015). Self-Reports Versus Parental Perceptions of Health-Related Quality of Life Among Deaf Children and Adolescents. Journal of Deaf Studies and Deaf Education, 20(3), 275-282. https://doi.org/10.1093/deafed/env018

Punch, R., \& Hyde, M. (2011). Social Participation of Children and Adolescents with Cochlear Implants: A Qualitative Analysis of Parent, Teacher, and Child Interviews. The Journal of Deaf Studies and Deaf Education, 16(4), 474-493. https://doi.org/10.1093/deafed/enr001

Raven, J. (2000). The Raven's Progressive Matrices: Change and stability over culture and time. Cognitive Psychology, 41, 1-48. https://doi.org/10.1006/cogp.1999.0735

Ravens-Sieberer, U., \& Bullinger, M. (1998). Assessing health-related quality of life in chronically ill children with the German KINDL: first psychometric and content analytical results. Quality of Life Research, 7(5), 399-407. https://doi.org/10.1023/A:1008853819715

Ravens-Sieberer, U., \& Bullinger, M. (2000). KINDL: Questionnaire for Measuring Health-Related Quality of Life in Children and Adolescents-Revised Version: Manual. Retrieved from http://www.kindl.org/app/download/6676124784/KINDL_manual_English.pdf?t=1394710098

Razafimahefa-Raoelina, T., Farinetti, A., Nicollas, R., Triglia, J.-M., Roman, S., \& Anderson, L. (2016). Auto- et hétéroévaluation de la qualité de vie des enfants implantés cochléaires. Annales françaises d'Oto-rhino-laryngologie et de Pathologie Cervico-faciale, 133(1), 29-33. https://doi.org/10.1016/j.aforl.2015.01.012

Rekkedal, A. R. (2012). Assistive Hearing Technologies Among Students With Hearing Impairment: Factors That Promote Satisfaction. The Journal of Deaf Studies and Deaf Education, 17(4), 499-517. https://doi.org/10.1093/deafed/ens023

Rojhani Shirazi, M., Tonekaboni, S. H., Azargashb, E., Derakhshannia, M., \& Aghdasta, E. (2016). Exploring the Psychometric Properties of The Farsi Version of Quality of Life Kindl Questionnaire for 4-7 Year-Old Children in Iran. Iran J Child Neurol, 10(2), 42-52.

Rotsika, V., Coccossis, M., Vlassopoulos, M., Papaeleftheriou, E., Sakellariou, K., Anagnostopoulos, D. C., ... 
Skevington, S. (2011). Does the subjective quality of life of children with specific learning disabilities (SpLD) agree with their parents' proxy reports? Quality of Life Research, 20(8), 1271-1278. https://doi.org/10.1007/s11136-011-9857-z

Sakiz, H., Sart, Z. H., Börkan, B., Korkmaz, B., \& Babür, N. (2015). Quality of Life of Children with Learning Disabilities: A Comparison of Self-Reports and Proxy Reports. Learning Disabilities Research \& Practice, 30(3), 114-126. https://doi.org/10.1111/1drp.12060

Sarant, J., \& Garrard, P. (2014). Parenting Stress in Parents of Children with Cochlear Implants: Relationships Among Parent Stress, Child Language, and Unilateral Versus Bilateral Implants. The Journal of Deaf Studies and Deaf Education, 19(1), 85-106. https://doi.org/10.1093/deafed/ent032

Shrout, P. E., \& Fleiss, J. L. (1979). Intraclass Correlations: Uses in Assessing Rater Reliability. Psychological Bulletin, 86(2), 420-428. https://doi.org/10.1037/0033-2909.86.2.420

Stevanovic, D., Tadic, I., Novakovic, T., Kisic-Tepavcevic, D., \& Ravens-Sieberer U. (2013). Evaluating the Serbian version of the KIDSCREEN quality-of-life questionnaires: reliability, validity, and agreement between children's and parents' ratings. Quality of Life Research, 22(7), 1729-37. https://doi.org/10.1007/s11136-012-0286-4

Veland, J., Bru, E., \& Idsøe, T. (2014). Perceived socio-economic status and social inclusión in school: parental monitoring and support as mediators. Emotional and Behavioural Difficulties, 20(2), 173-188. https://doi.org/10.1080/13632752.2014.931018

Warner-Czyz, A. D., Loy, B., Roland, P. S., Tong, L., \& Tobey, E. A. (2009). Parent versus child assessment of quality of life in children using cochlear implants. International Journal of Pediatric Otorhinolaryngology, 73(10), 1423-1429. https://doi.org/10.1016/j.ijporl.2009.07.009

Warner-Czyz, A. D., Loy, B., Tobey, E. A., Nakonezny, P., \& Roland, P. S. (2011). Health-related quality of life in children and adolescents who use cochlear implants. International Journal of Pediatric Otorhinolaryngology, 75(1), 95-105. https://doi.org/10.1016/j.ijporl.2010.10.018

Wee, H. L., Lee, W. W. R., Ravens-Sieberer, U., Erhart, M., \& Li, S. C. (2005). Validation of the English version of the KINDLÒ generic children's health-related quality of life instrument for an Asian population - results from a pilot test. Quality of Life Research, 14, 1193-1200. https://doi.org/10.1007/s11136-004-2957-2

Wiefferink, C. H., Rieffe, C., Ketelaar, L., De Raeve, L., \& Frijns, J. H. (2013). Emotion Understanding in Deaf Children with a Cochlear Implant. The Journal of Deaf Studies and Deaf Education, 18(2), 175-186. https://doi.org/10.1093/deafed/ens042

Worsfold, S., Mahon, M., Yuen, H. M., \& Kennedy, C. (2010). Narrative skills following early confirmation of permanent childhood hearing impairment. Developmental Medicine \& Child Neurology, 52(10), 922-928. https://doi.org/10.1111/j.1469-8749.2010.03641.x

Yamaguchi, N., Poudel, K. C., Poudel-Tandukar, K., Shakya, D., Ravens-Sieberer, U., \& Jimba, M. (2010). Reliability and validity of a Nepalese version of the Kiddo-KINDL in adolescents. Biosci Trends, 4, 178-185.

Zhao, Y., Li, Y., Zheng, Z., Li, J., Nie, X., Jin, X., ... Ni, X. (2018). Health-Related Quality of Life in Mandarin-Speaking Children with Cochlear Implants. Ear \& Hearing, 40(3), 1-10. https://doi.org/10.1097/AUD.0000000000000633

Ziv, M., Most, T., \& Cohen, S. (2013). Understanding of Emotions and False Beliefs Among Hearing Children versus Deaf Children. The Journal of Deaf Studies and Deaf Education, 18(2), 161-174. https://doi.org/10.1093/deafed/ens073

\section{Copyrights}

Copyright for this article is retained by the author(s), with first publication rights granted to the journal.

This is an open-access article distributed under the terms and conditions of the Creative Commons Attribution license (http://creativecommons.org/licenses/by/4.0/). 